\title{
(2) OPEN ACCESS \\ Utility of routine screening for alpha-1 antitrypsin deficiency in patients with bronchiectasis
}

\author{
Luis Carreto, ${ }^{1}$ Meghan Morrison, ${ }^{2}$ Jackie Donovan, ${ }^{3}$ Simon Finch, ${ }^{4}$ Gan Liang Tan, ${ }^{5}$ \\ Tom Fardon, ${ }^{6,7}$ Robert Wilson, ${ }^{8}$ Elisabeth Furrie, ${ }^{9}$ Michael Loebinger, ${ }^{8}$ \\ James D Chalmers ${ }^{4}$
}

${ }^{1}$ Respiratory Medicine, Hospital Professor Fernando Fonseca (HFF), Lisbon, Portugal ${ }^{2}$ School of Medicine, University of Dundee, Dundee, UK ${ }^{3}$ Biochemistry, Royal Brompton and Harefield NHS Foundation Trust, London, UK ${ }^{4}$ Division of Molecular and Clinical Medicine, University of Dundee, Dundee, UK

${ }^{5}$ Respiratory and Critical Care Medicine, Singapore General Hospital, Singapore

${ }^{6}$ Respiratory Medicine, University of Dundee, Dundee, UK

${ }^{7}$ Respiratory Medicine, NHS Tayside, Dundee, UK

${ }^{8}$ Host Defence Unit, Division of Respiratory Medicine, Royal Brompton Hospital, London, UK ${ }^{9}$ Department of Immunology, Department of Medicine, Ninewells Hospital, Dundee, UK

\section{Correspondence to}

Dr James D Chalmers, Tayside Respiratory Research Group, University of Dundee, Dundee DD1 9SY, UK:

jchalmers@dundee.ac.uk

Received 12 October 2019 Revised 15 February 2020 Accepted 18 March 2020 Published Online First 17 April 2020

Check for updates

(C) Author(s) (or their employer(s)) 2020. Re-use permitted under CC BY-NC. No commercial re-use. See rights and permissions. Published by BMJ.

To cite: Carreto $L_{1}$

Morrison M, Donovan J, et al.

Thorax 2020:75:592-593.

\section{ABSTRACT}

Alpha-1 antitrypsin deficiency (AATD) is a cause of bronchiectasis. Guidelines for bronchiectasis from the British Thoracic Society do not recommend to routinely test patients for AATD. In contrast, guidelines for AATD recommend routine screening. This contradiction, in part, results from the lack of data from large studies performing comprehensive screening. We screened 1600 patients with bronchiectasis at two centres in the UK from 2012 to 2016. In total, only eight individuals with AATD were identified representing $0.5 \%$ of the overall population. We conclude that routine screening for AATD in bronchiectasis in the UK has a low rate of detection. Further studies are required in different geographical regions, which may have a higher prevalence of AATD.

Bronchiectasis is a heterogeneous airway disease characterised by chronic respiratory symptoms and permanent dilatation of bronchi. Guidelines from the European and British Thoracic Societies recommend systematic investigations for underlying causes, since there is specific treatment for some diseases that could have clinical and prognostic impact. $^{12}$

Alpha-1 antitrypsin deficiency (AATD) is a potential cause of bronchiectasis and augmentation therapy is licensed in several countries, particularly in cases of severe disease with airway obstruction. ${ }^{3}$ Prevalence of PiSZ and PiZZ phenotypes, the two most common phenotypes associated with lower serum alpha-1 antitrypsin (A1AT) levels and increased risk of lung disease, has been estimated to be $1: 900$ and 1:15.388, respectively, in the overall population in Scotland with a higher prevalence of 1:4440 reported in England. ${ }^{4}$

The clinical utility of AATD screening in bronchiectasis patients remains unclear. The British Thoracic Society guidelines currently recommend against screening for AATD-based primarily on the results of Pasteur et $a l^{5}$ who screened 150 patients with bronchiectasis and found a frequency of AATD which was not different to the general UK population. No patients with SZ or ZZ phenotype were identified in this study. ${ }^{5}$ A retrospective study of 202 patients with bronchiectasis from France (19911996) found a distribution of alpha-1 phenotypes that was not different to the distribution expected in the general population. ${ }^{6}$ In contrast, bronchiectasis has been reported frequently in patients with known AATD. ${ }^{7}$ For example Parr et al studied 74 patients with PiZZ genotype and found that 95\% had bronchiectasis affecting a mean of 3.7 lobes.
$27 \%$ had bronchiectasis affecting more than four lobes and daily sputum production. ${ }^{7}$ Based on data such as this, guidelines for AATD suggest screening all patients with bronchiectasis for AATD. ${ }^{8}$ This contradiction, where bronchiectasis guidelines recommend against screening while AATD guidelines recommend routine testing, results in part from the lack of any large prospective studies evaluating the results of routine prospective screening.

We, therefore, investigated if routine measurement of serum A1AT in the aetiological assessment of bronchiectasis was clinically useful in two large populations of UK adults.

New patients attending the Bronchiectasis Clinics at Ninewells Hospital and the Royal Brompton Hospital, London (RBH) for initial investigation of bronchiectasis aetiology were included in the study. All patients had documented bronchiectasis by high-resolution CT (HRCT) scans. Standardised testing for aetiologies of bronchiectasis was performed including A1AT testing, but also testing for allergic bronchopulmonary aspergillosis (ABPA), immunoglobulins, functional antibodies and serum electrophoresis. Serum A1AT level was measured according to the local laboratory standard procedures and in cases where the serum level was low, phenotyping was performed. At the Ninewells laboratory, the level for phenotyping was $1.0 \mathrm{~g} / \mathrm{L}$ and at $\mathrm{RBH}$ it was $1.3 \mathrm{~g} / \mathrm{L}$.

Between January 2012 and December 2016, 675 people with bronchiectasis were investigated at Ninewells Hospital and 925 patients were investigated at RBH. Characteristics of patients at both centres have been previously reported and are predominantly elderly females (median 67 years, $60 \%$ female).

At the Scottish centre, we identified 17 patients $(2.52 \%)$ with A1AT levels $<1 \mathrm{~g} / \mathrm{L}$ who went on to have phenotyping performed. In those with an abnormal A1AT level, the mean was $0.79 \mathrm{~g} / \mathrm{L}$ $(+/-0.18)$. Phenotypes were PiMZ in 13 patients (average $0.86 \mathrm{~g} / \mathrm{L}+/-0.09$ ), PiSZ in three patients (average $0.7 \mathrm{~g} / \mathrm{L}+/-0.06$ ) and PiZZ in one patient $(0.20 \mathrm{~g} / \mathrm{L}$. We, therefore, identified one patient with severe AATD disease (PiZZ) from 675 screened and three patients with moderate AATD disease (PiSZ). The minimum protective level of A1AT has been reported as $0.8 \mathrm{~g} / \mathrm{L}$. On this basis we identified six individuals with deficient A1AT levels.

From the 925 patients screened at RBH 254 patients had phenotyping performed due to a level $<1.3 \mathrm{~g} / \mathrm{L}$ of which 21 had levels $<1 \mathrm{~g} / \mathrm{L}$ equating to the Ninewells cut-off. From phenotyping we 


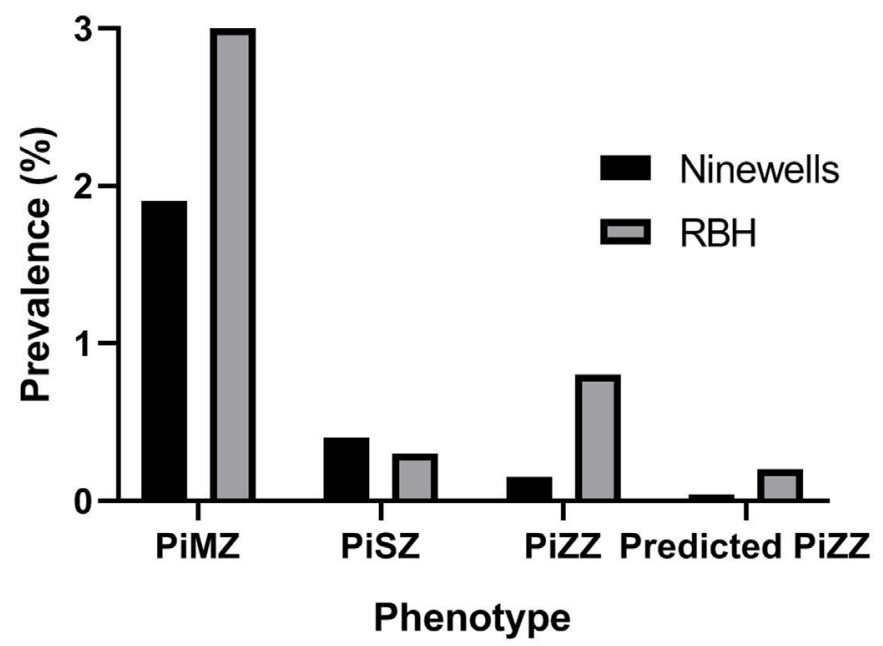

Figure 1 Frequency of different alpha-1 antitrypsin deficiency phenotypes in the two cohorts. Predicted values are the $\%$ of subjects expected to be identified in the general population based on reported population frequencies of PiZZ alpha-1 antitrypsin deficiency (unweighted prevalence estimates). ${ }^{34}$ RBH, Royal Brompton Hospital.

identified seven patients with PiZZ with an average level of $0.23 \mathrm{~g} / \mathrm{L}(0.05)$, three patients with PiSZ or PiS where the second allele could not be identified with an average of 0.93 (0.23). Twenty-eight patients were identified with PiMZ with an average of $1.01 \mathrm{~g} / \mathrm{L}(0.16)$. Eight patients had A1AT levels below the protective threshold of $0.8 \mathrm{~g} / \mathrm{L}$. Results are summarised in figure 1.

Augmentation therapy is recommended only to non-smoking patients with pulmonary emphysema and reduced or progressive decline on lung function. ${ }^{3}$ Non-smoking PiMZ individuals are not known to have increased risk of lung disease ${ }^{9}$ and PiSZ phenotype is not usually an indication for augmentation therapy, therefore, in 675 bronchiectasis patients, only one $(0.15 \%)$ patients in Scotland and 7 (0.8\%) in England had severe AATD that could possibly benefit from augmentation therapy. The slightly higher prevalence in England may reflect true differences as the reported prevalence is higher in England, or differences in the characteristics of patients referred to each centre.

In the UK, National Health System, A1AT serum assay and phenotyping costs were $£ 2.45$ and $£ 35$.50, respectively, which means that the total cost of screening in this project was $£ 2257.25$ to identify a single individual eligible for treatment in the Scottish site and $£ 11283.25$ to identify seven patients eligible for treatment in the English site. The higher costs at the English site reflect a higher number of patients included and the lower threshold for phenotyping of $1.3 \mathrm{~g} / \mathrm{L}$.

Augmentation therapy have been shown to reduce, but not eliminate, emphysema progression ${ }^{3}$ and to reduce the frequency of hospital admissions for acute exacerbations of chronic obstructive pulmonary disease. ${ }^{10}$ However, to our knowledge, there have been no studies evaluating clinical benefits for bronchiectasis patients with AATD. It is important to note that augmentation therapy, despite its clinical benefits in selected patients, is not available in some countries, including the UK.

Early diagnosis of AATD is important for much more than augmentation therapy, as these patients also benefit from smoking cessation programmes and genetic counselling. Awareness that patients have impaired protease-anti-protease balance may lead to closer monitoring and a lower threshold to treat chronic infection. However, our findings show that the prevalence of AATD in bronchiectasis patients is relatively low compared with other reported aetiologies which are routinely screened for such as ABPA, and that implementation of routine screening of these patients does not significantly impact on clinical management. Our results are derived from two UK centres and a predominantly Caucasian population. It is possible that a higher rate of detection of AATD would be found in other geographical regions in the UK, or in other countries. The study has limitations including that we screened two unselected bronchiectasis populations and did not collect detailed phenotypic data. We cannot, therefore, comment on whether more focused screening, for example, by limiting testing to those with airflow obstruction or CT detected emphysema, would have a great pickup rate. This will require further studies. A multicentre European cohort study that incorporates standardised testing for AATD is currently enrolling (NCT03791086) and will provide broader prevalence estimates as well as more detailed phenotypic data.

In summary, screening of an unselected UK bronchiectasis population for AATD identifies severe AATD in less than $1 \%$ of cases.

Twitter Tom Fardon @dundeechest

Contributors Study design: JDC, TF, EF, RW and ML. Collected data: LC, MM, JD, SF, GLT, TF, ML and JDC. Performed analysis: LC, MM, ML and JDC. Wrote the manuscript $\mathrm{LC}$ and JDC. Edited the manuscript and approval the final version: all authors.

Funding This study was funded by British Lung Foundation (BLF chair of respiratory research).

Competing interests ML declares personal fees from Grifols, Bayer, Polyphor and Astrazeneca. JDC declares research grants or personal fees from Glaxosmithkline, Boehringer-Ingelheim, Astrazeneca, Pfizer, Bayer, Grifols, Aradigm, Napp and Insmed outside the submitted work.

Patient consent for publication Not required.

Provenance and peer review Not commissioned; externally peer reviewed.

Open access This is an open access article distributed in accordance with the Creative Commons Attribution Non Commercial (CC BY-NC 4.0) license, which permits others to distribute, remix, adapt, build upon this work non-commercially, and license their derivative works on different terms, provided the original work is properly cited, appropriate credit is given, any changes made indicated, and the use is non-commercial. See: http://creativecommons.org/licenses/by-nc/4.0/.

\section{REFERENCES}

1 Polverino E, Goeminne PC, McDonnell MJ, et al. European respiratory Society guidelines for the management of adult bronchiectasis. Eur Respir J 2017; 50:1700629.

2 Hill AT, Sullivan AL, Chalmers JD, et al. British thoracic Society guideline for bronchiectasis in adults. Thorax 2019;74:1-69.

3 Miravitlles M, Dirksen A, Ferrarotti I, et al. European respiratory Society statement: diagnosis and treatment of pulmonary disease in $\alpha_{-}$, antitrypsin deficiency. Eur Respir J 2017;50:1700610.

4 Blanco I, Bueno P, Diego I, et al. Alpha-1 antitrypsin Pi* Z gene frequency and $\mathrm{Pi}^{\star} \mathrm{ZZ}$ genotype numbers worldwide: an update. Int J Chron Obstruct Pulmon Dis 2017;12:561-9.

5 Pasteur MC, Helliwell SM, Houghton SJ, et al. An investigation into causative factors in patients with bronchiectasis. Am J Respir Crit Care Med 2000;162:1277-84.

6 Cuvelier A, Muir JF, Hellot MF, et al. Distribution of alpha(1)-antitrypsin alleles in patients with bronchiectasis. Chest 2000;117:415-9.

7 Parr DG, Guest PG, Reynolds JH, et al. Prevalence and impact of bronchiectasis in alpha1-antitrypsin deficiency. Am J Respir Crit Care Med 2007;176:1215-21.

8 Sandhaus RA, Turino G, Brantly ML, et al. The diagnosis and management of alpha-1 antitrypsin deficiency in the adult. Chronic Obstr Pulm Dis 2016;3:668-82.

9 Hersh CP, Dahl M, Ly NP, et al. Chronic obstructive pulmonary disease in alpha1antitrypsin PI MZ heterozygotes: a meta-analysis. Thorax 2004;59:843-9.

10 Dirksen A, Piitulainen E, Parr DG, et al. Exploring the role of CT densitometry: a randomised study of augmentation therapy in alpha1-antitrypsin deficiency. Eur Respir J 2009;33:1345-53. 